Check for updates

Cite this: RSC Adv., 2018, 8, 10207

\title{
Effects of combined pretreatment of dilute acid pre-extraction and chemical-assisted mechanical refining on enzymatic hydrolysis of lignocellulosic biomass
}

\begin{abstract}
Wei Liu, (D) *ab Wei Chen, ${ }^{\text {ab }}$ Qingxi Hou, ${ }^{a}$ Si Wang ${ }^{a}$ and Fang Liu ${ }^{a}$
An efficient enzymatic hydrolysis of lignocellulosic biomass into fermentable sugars depends greatly on the pretreatment of raw materials. In this study, a combination of dilute acid pre-extraction and chemicalassisted mechanical refining was used to pretreat wood lignocellulosic biomass for subsequent enzymatic hydrolysis. This work analyzed the surface lignin concentration, specific surface area, crystallinity, fines content, fiber length, and kink index of the resultant pulp substrates and their effects on the enzymatic hydrolysis. The results showed that the combined pretreatment significantly enhanced the enzymatic hydrolysis efficiency, and the maximum glucose conversion yield and glucose concentration were $93.32 \%$ and $21.41 \mathrm{~g} \mathrm{~L}^{-1}$, respectively. It is found that the surface lignin concentration, specific surface area, and fines content significantly affected the enzymatic hydrolysis.
\end{abstract}

Received 24th November 2017

Accepted 19th February 2018

DOI: $10.1039 / c 7 r a 12732 d$

rsc.li/rsc-advances

methods, dilute acid pre-extraction is favorable for industrial applications, and has been applied in a wide range of feedstocks. Acid pre-extraction can partially dissolve hemicelluloses from lignocellulosic biomass, because the glycosidic bonds that exist in hemicelluloses are susceptible to acid. ${ }^{7}$ Dilute acid preextraction has been widely recognized and used because of its numerous advantages, such as its high efficiency, simple process, and low cost. ${ }^{4,8}$ It has been reported that dilute acid pre-extraction can improve the enzymatic hydrolysis efficiency of maize stems by enhancing the accessibility of cellulose and changing the lignin distribution. ${ }^{9}$ In addition, mechanical refining is a common and typical technology used in pulp and paper industry to separate fibers, and further achieve fibrillation of fibers. Recently, many researchers have focused on mechanical refining and have attempted to use it as an approach to pretreat lignocellulosic biomass. It is also reported that mechanical refining can increase the accessibility of cellulose to enzymes and improve sugar yields. ${ }^{10}$ In the previous work, we found that: (1) the dilute acid pre-extraction prior to pulping can remove most of hemicelluloses from raw materials, and significantly reduce the mechanical refining energy in the following pulping process; and (2) the synergistic effects of chemical pre-extraction and chemi-thermomechanical refining on the enzymatic hydrolysis of wheat straw were remarkable. ${ }^{\mathbf{1 1 , 1 2}}$ The acid pre-extraction can remove most of hemicelluloses from the lignocellulosic biomass for the production of hemicelluloses-based products, like sugars for the biofuels, xylitol, acetic acid, furfural, and so on. The acid pre-extraction can help to reduce the following mechanical refining energy. Consequently, it is expected that the combination of chemical
${ }^{a}$ Tianjin Key Laboratory of Pulp \& Paper, Tianjin University of Science \& Technology, Tianjin 300457, China.E-mail:wei.liu2009@hotmail.com

${ }^{b}$ State Key Laboratory of Pulp and Paper Engineering, South China University of Technology, Guangzhou 510640, China 
pretreatment with mechanical refining can be applied in a high value-added utilization of biomass, especially regarding a mechanical pulp mill-based integrated biorefinery in the future.

Some researchers believe that the lignin content and distribution in the biomass substrates play a significant role in the enzymatic hydrolysis of lignocellulosic biomass, as well as the surface lignin concentration (SLC) and specific surface area (SSA). ${ }^{13-15}$ Yang et al. found that the cellulose ultrastructure, mainly crystallinity index (CrI) and degree of polymerization, was a relevant indicator to the enzymatic hydrolysis performance. ${ }^{16}$ However, the exact role of these different characteristics of the biomass substrates on enzymatic hydrolysis has still not been clearly defined due to the fact that biomass recalcitrance is complex, multivariate and interactional. Until now, there are rare studies that focus on the comprehensive assessing the significance of different characteristics' changes during the pretreatment on the enzymatic hydrolysis efficiency, especially for one kind of defined combined pretreatment. Thus, the objective of this study was to investigate the effects of combined pretreatment of dilute acid pre-extraction and chemicalassisted mechanical refining on the enzymatic hydrolysis of lignocellulosic biomass, and further to evaluate the effects of main pulp substrates' characteristics (SSA, SLC, CrI, fines content, fiber length and kink index) on the enzymatic hydrolysis performance.

\section{Experimental}

\subsection{Materials}

The poplar (triploid Populus tomentosa) wood chips were chosen as one representative example of lignocellulosic biomass. The poplar wood chips, collected from a paper mill in Shandong Province, China, with the sizes of $20 \mathrm{~mm}(H) \times 20 \mathrm{~mm}(W) \times$ $3 \mathrm{~mm}(D)$, were screened to remove knots and dirts, and washed with deionized water. The primary chemical compositions of the wood chips were: glucan $42.25 \%$, xylan $14.80 \%$, arabinan $0.29 \%$, acetyl groups $2.59 \%$, acid insoluble lignin (AIL) $21.75 \%$, acid soluble lignin (ASL) $4.32 \%$, and ethanol extractives $1.88 \%$, as shown in Table 1, which were determined according to the methods of NREL-510-42618 and NREL-510-42619.
Enzymes of Cellic CTec2 and Cellic HTec2 were purchased from Novozymes, China. The activities of CTec2 and HTec2 were $61 \mathrm{FPU} \mathrm{mL} \mathrm{mL}^{-1}$ and $85731 \mathrm{U} \mathrm{mL}^{-1}$, respectively. Standards of $\mathrm{D}-(+)$-glucose, $\mathrm{D}-(+)$-xylose and $\mathrm{L}-(+)$-arabinose were obtained from Sigma-Aldrich, Acros Organics, and Alfa Aesar Chemical, respectively. A furfural standard (2-furaldehyde, 99\%) and acetic acid (49-51\%) were obtained from Sigma-Aldrich, while 5hydroxymethylfurfural (HMF, 99\%) was obtained from Energy Chemical. Sulfuric acid $\left(\mathrm{H}_{2} \mathrm{SO}_{4}, 98 \%\right)$, sodium hydroxide $(\mathrm{NaOH},>96 \%)$, and other chemicals were of analytical grade.

\subsection{Dilute acid pre-extraction of wood chips}

The dilute sulfuric acid pre-extraction was conducted in a $6 \mathrm{~L} \mathrm{M}$ / $\mathrm{K}$ digester (M/K Systems Inc., USA). An equivalent of $150 \mathrm{~g}$ (ovendried) wood chips were added into the digester and mixed with preheated deionized water $\left(80^{\circ} \mathrm{C}\right)$ at a liquid/solid ratio of $10: 1$ $\mathrm{L} / \mathrm{kg}$. The charge of sulfuric acid is $1.0 \%$ based on the ovendried wood chips weight. The temperature was then raised to the desired value at a rate of $2{ }^{\circ} \mathrm{C} \mathrm{min}^{-1}$. After the pre-extraction, the pre-extracted wood chips were removed from the digester, and washed thoroughly with deionized water until the filtrate was colorless and its $\mathrm{pH}$ was neutral, the wood chips were then stored for the future analysis. The yields of wood chips were determined, i.e., the oven-dried weight of pre-extracted wood chips divided by the oven-dried wood chips weight.

In this study, the acid pre-extraction severity factor (SF, expressed as $\ln R_{0}$ ) depends upon the pre-extraction temperature and the duration time is used to quantify the pre-extraction intensity: ${ }^{17}$

$$
\ln R_{0}=\frac{T-100}{14.75}+\ln t
$$

where $t$ is the duration time in minutes, and $T$ is the reaction temperature in ${ }^{\circ} \mathrm{C}$.

\subsection{Chemical-assisted mechanical refining of the pre- extracted wood chips}

The pre-extracted wood chips were well mixed with sodium hydroxide $(\mathrm{NaOH})$ and sodium sulphite $\left(\mathrm{Na}_{2} \mathrm{SO}_{3}\right)$ in a polyethylene bag at $40 \%(\mathrm{w} / \mathrm{w})$ consistency, and then put in a water bath at $80{ }^{\circ} \mathrm{C}$ for $30 \mathrm{~min}$. The chemical charges were as follows:

Table 1 The main chemical compositions of pre-hydrolysates (based on o.d. raw material)

\begin{tabular}{|c|c|c|c|c|c|}
\hline Temperature $\left({ }^{\circ} \mathrm{C}\right)$ & 120 & 150 & 150 & 150 & 150 \\
\hline Time (min) & 30 & 20 & 40 & 60 & 80 \\
\hline SF & 2.07 & 2.77 & 3.07 & 3.25 & 3.38 \\
\hline Glucose (\%) & $0.09 \pm 0.01$ & $0.22 \pm 0.01$ & $0.33 \pm 0.00$ & $0.54 \pm 0.09$ & $0.45 \pm 0.02$ \\
\hline Xylose $(\%)$ & $0.17 \pm 0.00$ & $1.98 \pm 0.01$ & $4.35 \pm 0.01$ & $5.95 \pm 0.05$ & $6.92 \pm 0.03$ \\
\hline Arabinose (\%) & $0.11 \pm 0.00$ & $0.15 \pm 0.04$ & $0.18 \pm 0.00$ & $0.19 \pm 0.01$ & $0.20 \pm 0.00$ \\
\hline Acetic acid (\%) & $\mathrm{ND}^{a}$ & $0.61 \pm 0.02$ & $1.73 \pm 0.98$ & $1.54 \pm 0.58$ & $2.10 \pm 0.14$ \\
\hline Furfural (\%) & $0.03 \pm 0.00$ & $0.09 \pm 0.01$ & $0.14 \pm 0.00$ & $0.18 \pm 0.01$ & $0.26 \pm 0.00$ \\
\hline $\operatorname{HMF}(\%)$ & ND & ND & $0.01 \pm 0.00$ & $0.01 \pm 0.00$ & $0.01 \pm 0.00$ \\
\hline Acid insoluble materials (\%) & $0.50 \pm 0.00$ & $1.46 \pm 0.01$ & $1.72 \pm 0.00$ & $2.08 \pm 0.00$ & $2.20 \pm 0.01$ \\
\hline Acid soluble lignin (\%) & $0.01 \pm 0.00$ & $0.22 \pm 0.01$ & $0.35 \pm 0.00$ & $0.46 \pm 0.01$ & $0.46 \pm 0.03$ \\
\hline Sum $(\%)$ & $0.90 \pm 0.01$ & $4.73 \pm 0.11$ & $8.81 \pm 0.99$ & $10.95 \pm 0.75$ & $12.60 \pm 0.23$ \\
\hline
\end{tabular}

${ }^{a} \mathrm{ND}$, not detected. Data are presented as means of \pm SDs of 3 replicates. 
$3.0 \% \mathrm{NaOH}, 4.0 \% \mathrm{Na}_{2} \mathrm{SO}_{3}$ based on the oven-dried weight of the pre-extracted wood chips. During this period, the bag was kneaded thoroughly every $5 \mathrm{~min}$ to ensure a uniform reaction. The chemically treated wood chips were then refined in a defibrator (model D, Vrena Mek Co., Sweden) for pressurized refining according to the following conditions: $40 \%(\mathrm{w} / \mathrm{w})$ consistency, and $0.65 \mathrm{MPa}$ for $5 \mathrm{~min}$. The second-stage refining was performed in a KRK high-consistency disk refiner (model 2500-II, Kumagai Riki Kogyo Co. Ltd., Japan) with a refiner gap of $0.1 \mathrm{~mm}$ at $15 \%(\mathrm{w} / \mathrm{w})$ consistency. The secondstage refining was repeated twice to obtain the separated pulp fibers. The refined pulp fibers were screened using a Somervilletype screen (model 535, Lorentzen \& Wettre Co. Ltd., Sweden) with a $0.15 \mathrm{~mm}$ slot size. The screened pulp fibers were then thickened to about $30 \%(\mathrm{w} / \mathrm{w})$ consistency. The obtained pulp fibers were used as the pulp substrates for the following enzymatic hydrolysis.

\subsection{Enzymatic hydrolysis}

The enzymatic hydrolysis was performed in a $250 \mathrm{~mL}$ flask at a solid content of $4.0 \%(\mathrm{w} / \mathrm{w})(\mathrm{pH} 4.8)$ on a shaking incubator (IKA KS 4000i control, IKA, Germany) at $50{ }^{\circ} \mathrm{C}$ and $180 \mathrm{rpm}$ for $72 \mathrm{~h}$. The enzymes loading were $20 \mathrm{FPU} \mathrm{g}^{-1}$ substrates for Cellic CTec2 and $60 \mathrm{IU} \mathrm{g}^{-1}$ substrate for Cellic $\mathrm{HTec} 2$, respectively. The glucose measurement was conducted using an SBA biological sensor (SBA-40C, Biology Research Institute of Shandong Academy of Sciences, China). The conversion yield of cellulose to glucose was calculated as follows:

$$
\text { Conversion yield of cellulose to glucose }(\%)=\frac{G}{G_{\mathrm{s}}} \times 100
$$

where $G_{\mathrm{S}}$ is the amount of glucose in pulp substrates, and $G$ is the amount of glucose in test samples. ${ }^{12}$

\subsection{Determination of surface lignin concentration of pulp substrates}

The X-ray photoelectron spectroscopy (XPS) was used to determine the SLC of the wood chips and pulp substrate. Before analysis, the samples were extracted with acetone in Soxhlet extractor according to the standard of TAPPI T280, then the extracted samples were washed thoroughly with deionized water in order to remove the extractives. The extracted samples were then used for the XPS analysis. The XPS analysis was conducted using an X-ray photoelectron spectrometer (PHI $1600, \mathrm{USA}$ ) equipped with a monochromatic $\mathrm{Al} \mathrm{K} \alpha \mathrm{X}$-ray source, using the pass energy $200 \mathrm{eV}$. The photoelectron collection was at 90 degrees in relation to the sample surface. The analyzed spot size was $400 \mu \mathrm{m}$ and at least three different areas were measured on each sample. Each measurement took about $3 \mathrm{~min}$. The SLC was calculated according to the equation:

$$
\text { Surface lignin concentration }=\frac{\mathrm{O} / \mathrm{C}_{\text {sample }}-\mathrm{O} / \mathrm{C}_{\text {carbohydrates }}}{\mathrm{O} / \mathrm{C}_{\text {lignin }}-\mathrm{O} / \mathrm{C}_{\text {carbohydrates }}}
$$

where $\mathrm{O} / \mathrm{C}_{\text {carbohydrates }}$ is $0.83, \mathrm{O} / \mathrm{C}_{\text {lignin }}$ is $0.33 .{ }^{18}$

\subsection{Determination of specific surface area of pulp substrates}

The SSA of pulp substrates was determined following the dye adsorption procedure with direct sky blue 6B. ${ }^{19}$ About $1.00 \mathrm{~g}$ of the sample was put into the dye solution at the solid/liquid ratio of $1 / 100 \mathrm{~g} \mathrm{~mL}^{-1}$. $\mathrm{NaCl}$ was added into the suspension at the ratio $20 \mathrm{wt} \%$ based on the oven-dried weight of pulp. The mixture was placed in a water bath $\left(60{ }^{\circ} \mathrm{C}\right)$ for $28 \mathrm{~h}$. The solution's absorbance was measured using an ultraviolet spectrophotometer (UV-1600, Beijing Rayleigh Analytical Instrument Co. Ltd., China) at $600 \mathrm{~nm}$, and the dye concentration of the solution was calculated according to the standard curve of direct sky blue 6B. The SSA, $A_{\text {cell }}\left(\mathrm{m}^{2} \mathrm{~g}^{-1}\right)$, was calculated according to following equation:

$$
A_{\text {cell }}=6.024 \times 10^{23}[S]_{\mathrm{f}} A_{\mathrm{d}} / M
$$

where $A_{\mathrm{d}}$ is the area occupied by each dye molecule, considered to be $240 \times 10^{-20} \mathrm{~m}^{2} ; M$ is the molecular weight of dye molecules $\left(999.79 \mathrm{~g} \mathrm{~mol}^{-1}\right) ;[S]_{\mathrm{f}}$ is the saturation value for the adsorption of dye on the fibers, $\mathrm{g} \mathrm{kg}^{-1}$, which can be obtained following the Langmuir adsorption in the following equation: ${ }^{20}$

$$
1 /[D]_{\mathrm{f}}=1 /\left(K[S]_{\mathrm{f}} \times[D]_{\mathrm{s}}\right)+1 /[S]_{\mathrm{f}}
$$

where $[D]_{\mathrm{f}}$ is the amount of dye adsorbed on the pulp, $\mathrm{g} \mathrm{kg}^{-1}$; $[D]_{\mathrm{S}}$ is the initial concentration of dye, $\mathrm{g} \mathrm{L}^{-1} ; K$ is a constant.

\subsection{Crystallinity index of pulp substrates}

The crystallinity index (CrI) of pulp substrates was determined using X-ray diffraction (XRD, D/max2500 PC, Rigaku Co., Ltd., Japan). Prior to the determination of crystallinity, the pulp substrates were freeze-dried. In this part, the pulp substrates were scanned at $30 \mathrm{kV}$ and $20 \mathrm{~mA}$ in a $2 \theta$ range between $5^{\circ}$ and $50^{\circ}$ at $8.0^{\circ} \mathrm{min}^{-1}$. The peak area method was adopted to estimate the CrI based on the following equation: ${ }^{21}$

$$
\mathrm{CrI}=\frac{I_{\mathrm{c}}}{I_{\mathrm{c}}+I_{\mathrm{a}}} \times 100 \%
$$

where $I_{\mathrm{c}}$ is the peak area of the crystalline region; $I_{\mathrm{a}}$ is the peak area of the amorphous region.

\subsection{Fiber analysis of pulp substrates}

The fines content, length and kink index of pulp substrates were measured using a fiber quality analyzer (FQA, Lorentzen \& Wettre, Sweden).

All the above experiments were repeated three times, and the obtained results were analyzed at a 95\% confidence interval.

\subsection{SEM analysis of pulp substrates}

The surface morphology of the wood chips and pulp substrate was analyzed using a SEM (JSM-IT300, Japan Electron Optics Laboratory Co. Ltd., Japan). The samples were oven-dried in a vacuum oven at $50{ }^{\circ} \mathrm{C}$ for $4 \mathrm{~h}$, and then sputter coated with gold. ${ }^{22}$ 


\section{Results and discussion}

\subsection{Chemical compositions of pre-hydrolysates}

The main chemical compositions of the pre-hydrolysates derived from the acid pre-extraction of wood chips under different pre-extraction intensities (indexed by SF) are listed in Table 1 . The total content of the organic compositions in prehydrolysates increased from 0.90 to $12.60 \mathrm{wt} \%$ when the SF increased from 2.07 to 3.38. The increase of organic content in the pre-hydrolysates was attributed to the dissolution of hemicelluloses and part of lignin in wood chips, as shown in Table 1. The concentration of xylose was the highest, and it increased as the SF increased. The glucose content in the pre-hydrolysates was very low (the maximum value was $0.54 \mathrm{wt} \%$ ), indicating that degradation of cellulose was limited. The acetic acid released in the acid pre-extraction process can further promote the dissolution of carbohydrates in wood chips, and consequently destroy the lignin-carbohydrate complex structure. When the acid pre-extraction intensity was 3.38, xylose (6.92 $\mathrm{wt} \%)$, acetic acid (2.10 $\mathrm{wt} \%)$ and acid insoluble materials $(2.20 \mathrm{wt} \%)$ were the primary components present in the prehydrolysates. These components could potentially be collected and used to generate bio-based products. Furthermore, the removal of these components would reduce energy consumption in the subsequent mechanical refining process. ${ }^{11}$ Other studies have also proven that the removal of hemicelluloses increased the pore size of the fibers, and further increased the accessibility of cellulose to enzymes. ${ }^{23}$

\subsection{Chemical compositions of resultant pulp substrates}

The main chemical compositions of resultant pulp substrates are shown in Fig. 1. The results showed that the contents of glucan and acid insoluble lignin (AIL) increased somewhat while the contents of xylan and acid soluble lignin (ASL) decreased as the acid pre-extraction intensity increased. The reduction of xylan was caused by its degradation and dissolution during the acid pre-extraction. The increase in glucan and acid-insoluble lignin were resulted from their high stability, and the reduction of xylan and acid soluble lignin in the acid pre-

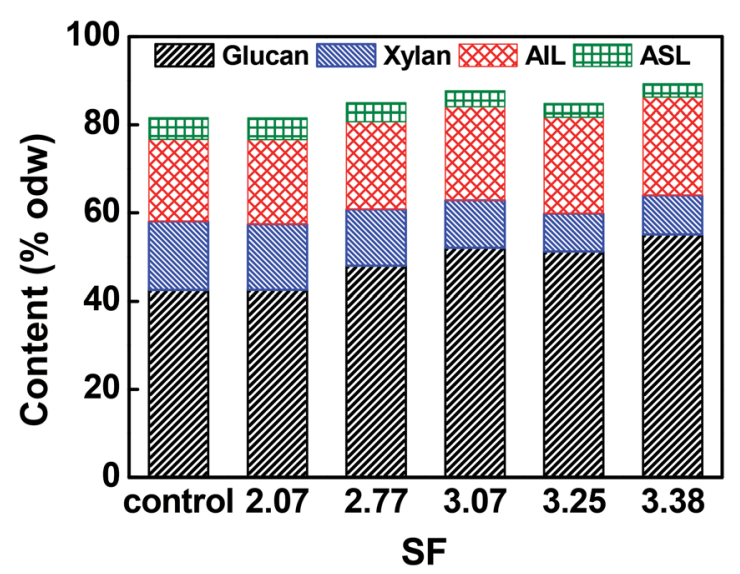

Fig. 1 The main chemical compositions of pulp substrates. extraction. ${ }^{24}$ Pingali et al. found that the reduction in the hemicelluloses or xylan content initiated at $125{ }^{\circ} \mathrm{C}$, reduced significantly from $150{ }^{\circ} \mathrm{C}$ during the dilute acid pretreatment; the hemicelluloses in hybrid poplar reached undetectable quantities by $2 \mathrm{~min}$ at $160{ }^{\circ} \mathrm{C}$ and switchgrass hemicellulose by $20 \mathrm{~min}$ at $160{ }^{\circ} \mathrm{C}$; the relative concentrations of glucan and lignin effectively increased due to the removal of hemicelluloses. ${ }^{25}$

\subsection{Effects of combined pretreatment on pulp substrates' enzymatic hydrolysis}

Fig. 2 shows the enzymatic hydrolysis of the resultant pulp substrates. The results showed that, compared to the control sample (i.e., the pulp substrates obtained from only chemicalassisted mechanical refining without acid pre-extraction), the conversion yield of cellulose to glucose increased remarkably after the combined pretreatment. It was found that the conversion yield of cellulose to glucose of the control sample was $45.31 \%$, while the enzymatic hydrolysis efficiency of the pulp substrate obtained at the SF of 3.07 was increased by $105.96 \%$, and the corresponding maximum conversion yield of cellulose to glucose and glucose concentration after 72 hours were $93.32 \%$ and $21.41 \mathrm{~g} \mathrm{~L}^{-1}$, respectively.

On the whole, $100 \mathrm{~g}$ poplar wood chips which mainly contain glucan $42.25 \mathrm{~g}$, xylan $14.80 \mathrm{~g}$, acid insoluble lignin $21.75 \mathrm{~g}$ and acid soluble lignin $4.32 \mathrm{~g}$. After the dilute acid pre-extraction under the severity factor of $3.07\left(150{ }^{\circ} \mathrm{C}, 40 \mathrm{~min}\right)$, the residues of the poplar wood chips (89.38 g) mainly contain glucan $41.72 \mathrm{~g}$, xylan $8.05 \mathrm{~g}$, acetyl groups $1.38 \mathrm{~g}$, acid insoluble lignin $19.31 \mathrm{~g}$ and acid soluble lignin $2.75 \mathrm{~g}$. Meanwhile, $4.35 \mathrm{~g}$ xylose, $0.33 \mathrm{~g}$ glucose, $0.18 \mathrm{~g}$ arabinose, $1.73 \mathrm{~g}$ acetic acid, $0.14 \mathrm{~g}$ furfural, $0.01 \mathrm{~g}$ HMF, $1.72 \mathrm{~g}$ acid insoluble materials, $0.35 \mathrm{~g}$ acid soluble lignin were mainly present in the pre-hydrolysates. Then, after the chemical-assisted mechanical refining, $76.81 \mathrm{~g}$ of the pulp substrates were obtained, which mainly contain glucan $39.99 \mathrm{~g}$, xylan $8.31 \mathrm{~g}$, acid insoluble lignin $16.26 \mathrm{~g}$ and acid soluble lignin $2.76 \mathrm{~g}$. During the enzymatic hydrolysis, $93.32 \%$ of the glucan in the pulp substrates can be converted

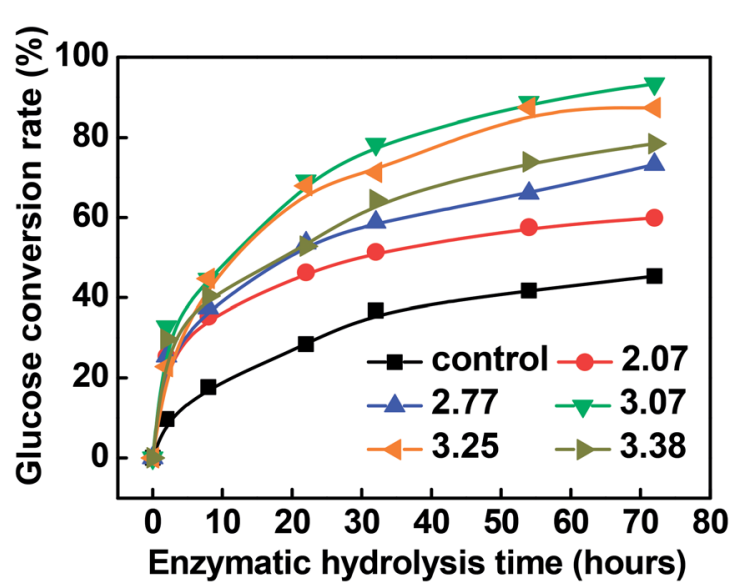

Fig. 2 Effects of combined pretreatment on pulp substrates' enzymatic hydrolysis. 
into glucose at the concentration of $21.41 \mathrm{~g} \mathrm{~L}^{-1}$, i.e., $41.47 \mathrm{~g}$ glucose can be obtained.

Ji et al. used acid to pretreat Miscanthus $\times$ giganteus internodes, including the rind and pith regions. Their results showed that the acid pretreatment on the pith effectively hydrolyzed $73.33 \%$ hemicelluloses, and the enzymatic hydrolysis yield reached $82.55 \% .{ }^{26}$ Pingali et al. found that, under the same experimental conditions, the dilute sulfuric acid pretreated switchgrass produced higher glucose yields ( $\sim 76 \mathrm{wt} \%$ ) than the pretreated hybrid poplar $(\sim 60 \mathrm{wt} \%) .{ }^{25}$

Compared with other methods, (1) it was reported that the highest glucan to glucose conversion (74.4\%) and the highest ethanol yield (52.6 $\mathrm{g} \mathrm{kg}^{-1}$ husks) were observed for hazelnut husks treated with $2.0 \% \mathrm{NaOH}$ for $90 \mathrm{~min}^{27}$ (2) Chacha et al. found that the yield of reducing sugars increased from $29 \%$ under the mildest conditions $\left(180^{\circ} \mathrm{C}, 1.5 \% \mathrm{SO}_{2}\right)$ to $91 \%$ under the most severe conditions $\left(225{ }^{\circ} \mathrm{C}, 3.0 \% \mathrm{SO}_{2}\right)$ at a given cellulose content. ${ }^{28}$

Other research has proven that dilute acid pre-extraction can lead to the redistribution of lignin and dissolution of hemicelluloses, resulting in a more open nanostructure, consequently improving the accessibility of cellulose to enzymes. ${ }^{24,26}$ In addition, during chemical treatment with $\mathrm{Na}_{2} \mathrm{SO}_{3}$ and $\mathrm{NaOH}$, the sulfonation of lignin can increase the hydrophilicity of lignin and consequently increase the hydrophilicity and swelling ability of pulp substrates, and further improve the accessibility of cellulose to enzymes. Therefore, the chemical treatment is believed to reduce the mechanical refining energy and help to improve the enzymatic hydrolysis efficiency of the resultant pulp substrates. Thus, different pulp substrates' characteristics were analyzed to evaluate the effects of combined pretreatment on the enzymatic digestibility of the resultant pulp substrates.

On the contrary, the present results also showed that increasing the acid pre-extraction intensity continuously did not achieve a higher conversion yield of cellulose to glucose, which was probably due to the changed physical and chemical properties of pulp substrates, especially the increased SLC at stronger pre-extraction conditions.

\subsection{Effects of combined pretreatment on pulp substrates' characteristics}

The resultant pulp substrates' characteristics (SLC, SSA, CrI, fines content, and fiber length, as well as kink index) were analyzed to access the ways in which the combined pretreatments affected the pulp substrates.

The SLC of the resultant pulp substrates are shown in Fig. 3. It is evident that the SLC of the pulp substrates was much lower than that of the control sample; the SLC decreased as the acid pre-extraction intensity increased (indexed by SF). In other words, the SLC decreased to a minimum of $43.28 \%$ when the SF increased to 3.07 , but it was increased slightly when the SF was continually increased. These changes were caused by the lignin removal during the acid pre-extraction, as shown in Table 1. At a higher pre-extraction intensity, the increase of SLC of pulp substrates was a result of the redeposition of lignin on pulp

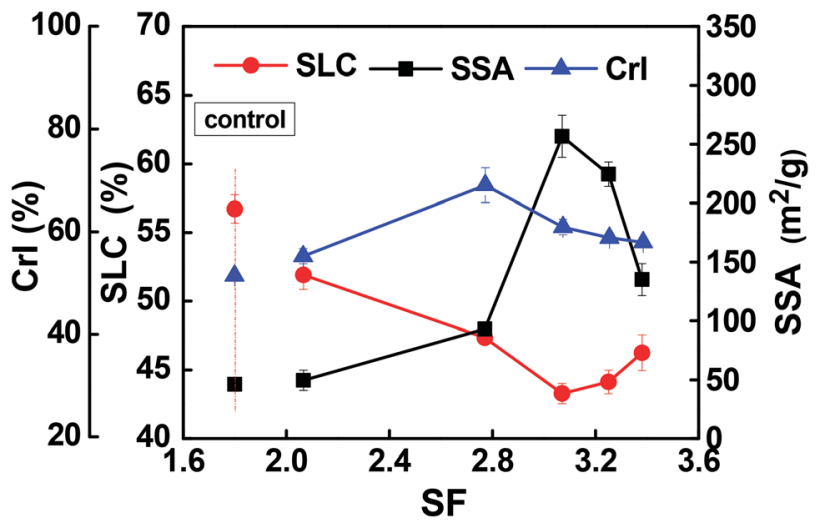

Fig. 3 Effects of combined pretreatment on specific surface area (SSA), surface lignin concentration (SLC) and $\mathrm{Crl}$ of pulp substrates.

substrates surface, ${ }^{29}$ which was confirmed by the following SEM analysis. Both the surface morphology and the chemical components on the surface of pulp substrates will affect the following enzymatic hydrolysis. Therefore, the surface morphology was analyzed by using SEM. As shown in Fig. 4, the surface of the control sample was smooth and had fewer wrinkles, while the surface of the pulp substrates that obtained from the combined pretreatment became coarser as the SF increased, and some granular materials appeared on the surface of pulp substrates when the SF was higher. Other studies reported that the hemicelluloses and lignin degradation products could be combined together and form lignin-like materials during pretreatment, termed pseudo-lignin, and then adsorbed on fibers surface. ${ }^{30}$ It is expected that the lignin distribution and the changes of carbohydrates will affect the following enzymatic hydrolysis. ${ }^{26,31}$

The SSA of the resultant pulp substrates is shown in Fig. 3. The results showed that the SSA was improved significantly after the combined pretreatment compared to the control sample $\left(45.51 \mathrm{~m}^{2} \mathrm{~g}^{-1}\right)$, and it reached a maximum value of $256.75 \mathrm{~m}^{2} \mathrm{~g}^{-1}$ when the SF was 3.07. However, when the SF increased from 3.07 to 3.38 , the SSA decreased, although it was still higher than that of the control sample. It is noteworthy that the variation tendency of a SSA showed a general negative relationship between the SLC of pulp substrates. This relationship could be due to the lignin adsorption on pulp substrates and likely reduced the SSA. Another possible reason is that increasing the acid pre-extraction intensity could destroy the lignocellulosic matrix structure, reduce the pore structure of the substrates, and further hinder the enzymatic hydrolysis of polysaccharides in lignocellulosic biomass. ${ }^{\mathbf{1 4}}$

The CrI of pulp substrates was evaluated, as shown in Fig. 3. It can be seen that the CrI of the control sample was the lowest $(51.39 \%)$, while that of the pulp substrates was the highest (69.06\%) when the SF was 2.77. As shown in Fig. 3, the CrI of pulp substrates decreased at a higher SF, which may indicate that the crystalline portion of the cellulose might have been attacked under stronger acid pre-extraction conditions. The increase of CrI is likely due to the removal of amorphous hemicelluloses during the acid pre-extraction. Meanwhile, after 

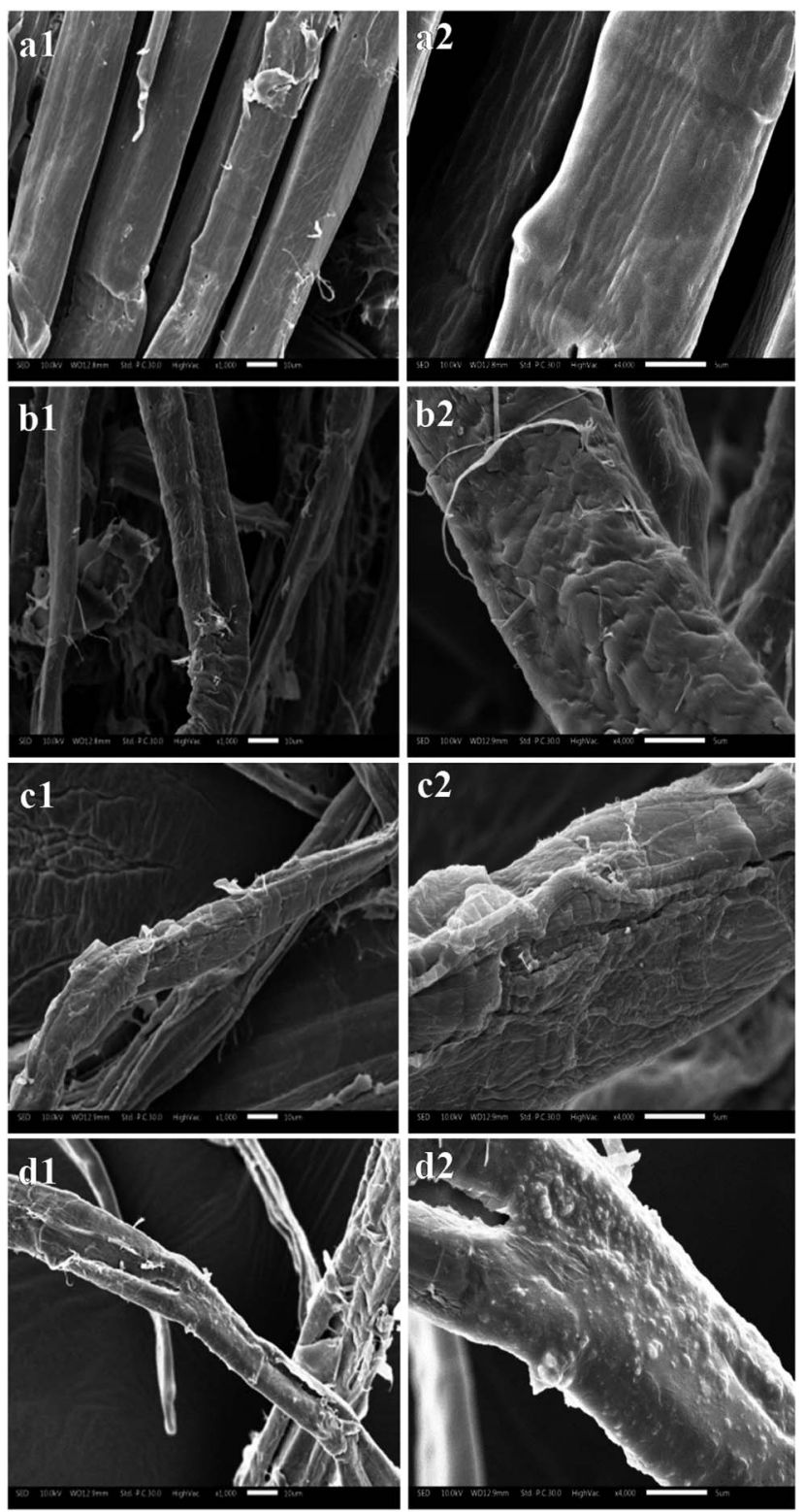

Fig. 4 SEM images of the pulp substrates at different acid preextraction intensities ((a), control; (b), SF of 3.07; (c), SF of 3.25; (d), SF of 3.38; left side, $\times 1000$; right side, $\times 4000$ ).

chemical-assisted mechanical refining, the CrI reduced as a result of the mechanical impacts on lignocellulosic biomass, and any decrease of CrI was accompanied by the alteration of other pulp substrates' characteristics, such as an increase in SSA or reduction of particle size..$^{13,32}$ Thus, there is a need to further study and evaluate the effects of CrI on enzymatic hydrolysis.

The fines content, length and kink index of pulp substrates were analyzed, and the results are shown in Table 2 . The fines contents were changed slightly with increasing the acid preextraction intensity; however, the maximum value of the fines content was $9.4 \%$ when the SF was 3.07, which is much higher than the value of the control sample. In addition, the fines content demonstrated a similar trend with the SSA and the
Table 2 The fiber quality analysis of pulp substrates

\begin{tabular}{llll}
\hline SF & $\begin{array}{l}\text { Fines content } \\
(\%)\end{array}$ & $\begin{array}{l}\text { Fiber length } \\
(\mathrm{mm})\end{array}$ & Kink index \\
\hline Control & 6.2 & 0.999 & 0.586 \\
2.07 & 7.7 & 0.978 & 0.605 \\
2.77 & 8.2 & 0.984 & 0.666 \\
3.07 & 9.4 & 0.975 & 0.684 \\
3.25 & 8.4 & 0.97 & 0.695 \\
3.38 & 7.9 & 0.964 & 0.772
\end{tabular}

conversion yield of cellulose to glucose. Meanwhile, an increase in fines content will lead to a larger SSA of pulp substrates, consequently resulting in improving the accessibility of pulp substrates. ${ }^{33}$ It is evident that, compared to the control sample, the fiber length reduced and the kink index increased after the combined pretreatment of acid pre-extraction and chemicalassisted mechanical refining. When the SF increased from 2.07 to 3.38 , the fiber length reduced from 0.978 to $0.964 \mathrm{~mm}$, and the kink index increased from 0.605 to 0.772 , respectively.

\subsection{Evaluating effects of pulp substrates' characteristics on enzymatic hydrolysis}

The enzymatic hydrolysis of reluctant pulp substrates was obviously enhanced by the combined pretreatment of acid preextraction and chemical-assisted mechanical refining. After the combined pretreatment, the characteristics of resultant pulp substrates were greatly changed. To fully understand the combined effects of dilute acid pre-extraction and chemicalassisted mechanical refining on enzymatic hydrolysis of lignocellulosic biomass, the relationships between the pulp substrates' characteristics and their enzymatic hydrolysis efficiency were studied by using a linear modeling analysis. Thus, the mathematical models of conversion yield of cellulose to glucose and enzymatic hydrolysis time were established using SigmaPlot 12.5 software. An appropriate regression equation of $y=a(1-\exp (-b \times x))+c(1-\exp (-d \times x))$ was obtained, and the analysis of variance (ANOVA) was conducted to estimate the effects of the regression model, as shown in Table 3.

Matlab software was used to calculate the definite integral of regression equation to characterize the enzymatic hydrolysis efficiency of the pulp substrates. ${ }^{34}$ It can be seen in Table 3 that the $R^{2}$ of each regression model was close to 1.0 and the $P$ values of each model were less than 0.0001 , indicating that the regression models were reliable enough.

The test of significance was conducted to evaluate the effects of pulp substrates' characteristics on the enzymatic hydrolysis efficiency. We established the linear relationships between the pulp substrates' characteristics and the value of definite integral that was obtained from regression models above, and the test of significance was conducted to evaluate the effects of the pulp substrates' characteristics on enzymatic hydrolysis (represent as correlation coefficient $|r|)$. The results of this analysis are listed in Table 4. The results of significance test showed that (1) SLC, SSA, and fines content had significant effects on the enzymatic hydrolysis of pulp substrates, while the significance of other 
Table 3 The mathematical models of the conversion yield of cellulose to glucose and enzymatic hydrolysis time

\begin{tabular}{|c|c|c|c|c|c|c|c|c|}
\hline \multirow[b]{2}{*}{$\mathrm{SF}$} & \multicolumn{5}{|c|}{ Parameters of regression equation } & \multicolumn{2}{|c|}{ Results of ANOVA } & \multirow{2}{*}{$\begin{array}{l}\text { Value of definite } \\
\text { integral }\end{array}$} \\
\hline & $a$ & $b$ & $c$ & $d$ & $R^{2}$ & $F$ values & $P$ values & \\
\hline Control & 7.158 & 0.8344 & 40.003 & 0.0395 & 0.9968 & 430.0393 & $<0.0001$ & 2433.213 \\
\hline 2.07 & 26.547 & 0.9579 & 36.922 & 0.0371 & 0.9969 & 589.2081 & $<0.0001$ & 3615.668 \\
\hline 2.77 & 26.046 & 0.9583 & 49.662 & 0.0343 & 0.9989 & 1740.351 & $<0.0001$ & 4098.407 \\
\hline 3.07 & 27.753 & 1.8037 & 65.062 & 0.0476 & 0.9947 & 343.9759 & $<0.0001$ & 5344.855 \\
\hline 3.25 & 30.48 & 1.0105 & 55.526 & 0.0362 & 0.9979 & 870.757 & $<0.0001$ & 4741.624 \\
\hline 3.38 & 29.58 & 1.24 & 59.344 & 0.0267 & 0.99 & 174.4653 & $<0.0001$ & 4481.097 \\
\hline
\end{tabular}

Table 4 The significance test of the correlation coefficients ${ }^{a}$

\begin{tabular}{lllll}
\hline Substrate characteristics & $R^{2}$ & $|r|$ & Effect type & Significance \\
\hline Surface lignin concentration & 0.964 & 0.982 & $\mathrm{~N}$ & $* *$ \\
Fines content & 0.8144 & 0.902 & $\mathrm{P}$ & $*$ \\
Specific surface area & 0.7804 & 0.883 & $\mathrm{P}$ & $*$ \\
Fiber length & 0.6361 & 0.798 & $\mathrm{~N}$ & \\
Kink index & 0.5174 & 0.719 & $\mathrm{P}$ & \\
CrI & 0.2923 & 0.541 & $\mathrm{~N}$ & \\
$r_{0.05}(3)=0.878, r_{0.01}$ & & & & \\
$(3)=0.959$ & & & \\
${ }^{a} \mathrm{~N}:$ negative; P: positive; $|r|=\sqrt{R^{2}} ;$;*', significant; '**', particularly \\
significant.
\end{tabular}

characteristics (CrI, fiber length and kink index) was relatively low; (2) the orders of these significant characteristics' significance were as follows: SLC $(|r|=0.982)>$ fines content $(|r|=$ $0.902)>$ SSA $(|r|=0.883)$; (3) SLC had a particularly significant negative influence on the enzymatic hydrolysis efficiency.

The SLC of pulp substrates has an unfavorable influence on the enzymatic hydrolysis, as it limits the accessibility of cellulose to enzymes; in this case, enzymes may irreversibly bind to the lignin on the substrates' surface. ${ }^{35,36}$ The SSA and fines content had a significantly positive impact on the enzymatic hydrolysis of the pulp substrates, which was consistent with other studies. ${ }^{26,37,38}$ However, the CrI and fiber length negatively affected the enzymatic hydrolysis. Therefore, it can be concluded that the combined pretreatment of dilute acid preextraction and chemical-assisted mechanical refining enhanced the enzymatic hydrolysis performance of wood chips obviously, which was attributed to reducing and redistributing the surface lignin, increasing the SSA and the fines content of the resultant pulp substrates.

\section{Conclusions}

The enzymatic hydrolysis of reluctant pulp substrates was enhanced by the combined pretreatment of dilute acid preextraction and chemical-assisted mechanical refining. Comparing with the pulp substrates without dilute acid preextraction, the enzymatic hydrolysis efficiency of pulp substrates after dilute acid pre-extraction (SF of 3.07) was increased by $105.96 \%$, and the maximum glucose conversion yield and glucose concentration were $93.32 \%$ and $21.41 \mathrm{~g} \mathrm{~L}^{-1}$, respectively. The combined pretreatment greatly changed the pulp substrates' characteristics. The mathematical analysis showed that SLC had a particularly significant negative influence on the enzymatic hydrolysis efficiency; however, the SSA and fines content had significantly positive impacts, while the other characteristics (CrI, fiber length and kink index) were not significant. The results also revealed that acid pre-extraction under very strong conditions could deteriorate the enzymatic hydrolysis performance due to the redeposition of lignin on the substrates' surface. It is expected that the application of acid pre-extraction followed by chemical-assisted mechanical refining would be of interest in mechanical pulp mill-based integrated biorefinery due to the advantages of providing additional revenue and enhancement of enzymatic hydrolysis of lignocellulosic biomass.

\section{Conflicts of interest}

The authors declare that they have no conflict of interest.

\section{Acknowledgements}

This work was financially supported by the National Natural Science Foundation of China (Grants 31770634 and 31300491), Natural Science Foundation of Tianjin City (17JCYBJC20600), National Key Research and Development Plan (Grant No. 2017YFB0307901), and Foundation of State Key Laboratory of Pulp and Paper Engineering. The authors would like to express their appreciation to Prof Xuejun Pan and Dr Pedram Fatehi for providing good suggestions on this paper.

\section{References}

1 A. A. Roos, T. Persson, H. Krawczyk, G. Zacchi and H. Stalbrand, Bioresour. Technol., 2009, 100(2), 763-769.

2 A. E. Farrell, R. J. Plevin, B. T. Turner, A. D. Jones, M. O'Hare and D. M. Kammen, Science, 2006, 311(5760), 506-508.

3 J. M. Lee, J. Shi, R. A. Venditti and H. Jameel, Bioresour. Technol., 2009, 100(24), 6434-6441.

4 N. Mosier, C. Wyman, B. Dale, R. Elander, Y. Y. Lee, M. Holtzapple and M. Ladisch, Bioresour. Technol., 2005, 96(6), 673-686.

5 J. Bian, F. Peng, X. P. Peng, X. Xiao, P. Peng, F. Xu and R. C. Sun, Carbohydr. Polym., 2014, 100(2), 211-217. 
6 X. Zhang, Q. Yuan and G. Cheng, Carbohydr. Polym., 2017, 156, 351-356.

7 F. Monlau, A. Barakat, E. Trably, C. Dumas, J. P. Steyer and H. Carrere, Crit. Rev. Environ. Sci. Technol., 2013, 43(3), 260-322.

8 A. Arora and D. J. Carrier, ACS Sustainable Chem. Eng., 2015, 3(10), 2423-2428.

9 S. N. Sun, S. L. Sun, X. F. Cao and R. C. Sun, Bioresour. Technol., 2016, 199, 49-58.

10 J. Y. Zhu and X. J. Pan, Bioresour. Technol., 2010, 101(13), 4992-5002.

11 W. Liu, Z. R. Yuan, C. B. Mao, Q. X. Hou and K. C. Li, Carbohydr. Polym., 2012, 87(1), 322-327.

12 J. P. Zhang, W. Liu, Q. X. Hou, J. W. Chen, N. P. Xu and F. Z. Ji, Bioresour. Technol., 2015, 175, 75-81.

13 P. Alvira, E. Tomás-Pejó, M. Ballesteros and M. J. Negro, Bioresour. Technol., 2010, 101(13), 4851-4861.

14 V. S. Chang and M. Holtzapple, Appl. Biochem. Biotechnol., 2000, 84-86(1), 5-37.

15 X. Z. Meng, Q. N. Sun, M. Kosa, F. Huang, Y. Q. Pu and A. J. Ragauskas, ACS Sustainable Chem. Eng., 2016, 4(9), 4563-4572.

16 B. Yang, Z. Y. Dai, S. Y. Ding and C. E. Wyman, Biofuels, 2011, 2(4), 421-450.

17 T. A. Lloyd and C. E. Wyman, Bioresour. Technol., 2005, 96(18), 1967-1977.

18 Q. H. Xu, Y. P. Wang, M. H. Qin, Y. J. Fu, Z. Q. Li, F. S. Zhang and J. H. Li, Bioresour. Technol., 2011, 102(11), 6536-6540.

19 A. M. Tang, G. Chen, P. M. Fan and W. Z. Liang, Application of direct dyes in paper making technology-to determine the surface area of wood fiber by dye adsorption, Dyest. Ind., 2000, 37(6), 24-27.

20 D. M. Hall and W. S. Perkins, Text. Res. J., 1971, 41(11), 923927.

21 K. Toba, H. Yamamoto and M. Yoshia, Cellulose, 2013, 20(2), 633-643.

22 D. Q. Zhao, F. Yang, Y. Dai, F. Y. Tao, Y. Shen, W. J. Duan, X. Z. Zhou, H. Y. Ma, L. Q. Tang and J. Li, Carbohydr. Polym., 2017, 174, 146-153.
23 R. P. Chandra, R. Bura, W. E. Mabee, A. Berlin, X. Pan and J. N. Saddler, Adv. Biochem. Eng./Biotechnol., 2007, 108, 6797.

24 S. V. Pingali, V. S. Urban, W. T. Heller, J. Mcgaughey, H. O'Neill, M. Foston, D. A. Myles, A. Ragauskas and B. R. Evans, Biomacromolecules, 2010, 11(9), 2329-2335.

25 S. V. Pingali, V. S. Urban, W. T. Heller, J. Mcgaughey, H. O'Neill, M. B. Foston, H. J. Li, C. E. Wyman, D. A. Myles, P. Langan, A. Ragauskas, B. Davison and B. R. Evans, ACS Sustainable Chem. Eng., 2017, 5(1), 426-435. 26 Z. Ji, X. Zhang, Z. Ling, R. C. Sun and F. Xu, Carbohydr. Polym., 2016, 154, 247-256.

27 Y. Copur, A. Tozluoglu and M. Ozkan, Bioresour. Technol., 2013, 129(2), 182-190.

28 N. Chacha, K. Toven, G. Mtui, J. Katima and G. Mrema, Cellul. Chem. Technol., 2011, 45(7), 495-501.

29 B. S. Donohoe, S. R. Decker, M. P. Tucker, M. E. Himmel and T. B. Vinzant, Biotechnol. Bioeng., 2008, 101(5), 913-925.

30 P. Sannigrahi, D. H. Kim, S. Jung and A. J. Ragauskas, Energy Environ. Sci., 2011, 4(4), 1306-1310.

31 F. Yang, P. Mitra, L. Zhang, L. Prak, Y. Verhertbruggen, J. S. Kim, L. Sun, K. J. Zheng, K. X. Tang, M. Auer, H. V. Scheller and D. Loque, Plant Biotechnol. J., 2013, 11(3), 325-335.

32 W. Zhang, M. Liang and C. H. Lu, Cellulose, 2007, 14(5), 447456.

33 J. Larsen, M. Ø. Petersen, L. Thirup, H. W. Li and F. K. Iversen, Chem. Eng. Technol., 2008, 31(5), 765-772.

34 W. Liu, B. Wang, Q. X. Hou, W. Chen and M. Wu, Bioresour. Technol., 2016, 206, 99-103.

35 R. Kumar and C. E. Wyman, Biotechnol. Prog., 2009, 25(3), 807-819.

36 Y. N. Zeng, S. Zhao, S. H. Yang and S. Y. Ding, Curr. Opin. Biotechnol., 2014, 27(6), 38-45.

37 S. L. Sun, J. L. Wen, M. G. Ma, R. C. Sun and G. L. Jones, Ind. Crops Prod., 2014, 56(3), 128-136.

38 C. Xu, F. Ma, X. Zhang and S. Chen, J. Agric. Food Chem., 2010, 58(20), 10893-10898. 